\title{
EFEITOS DE DOSES DE FÓSFORO EM MAMONEIRA (Ricinus communis L.), CULTIVAR 'CAMPINAS' *
}

\author{
Júlio Nakagawa** \\ A. M. Louis Neptune *** \\ F. Roberto Vieira **** \\ O. Cleante Bataglia ****
}

\section{RESUMO}

Nos últimos trabalhos de adubação, feitos no Estado de São Paulo, com mamoneira, tem-se observado que o fósforo é o fator limitante na produção de sementes.

Para observar como o fósforo atua no crescimento, na produção e nos teores de óleo e de macronutrientes nos frutos, foi realizado um ensaio de campo, utilizando-se cultivar "Campinas" e as doses de 0-40-80-120-150 e $200 \mathrm{~kg} / \mathrm{ha}$ de $\mathrm{P}_{2} \mathrm{O}_{5}$, num solo pobre, classificado como Latossolo Vermelho Escuro - fase arenosa.

Em relação ao tratamento sem fósforo, o incremento médio observado na produção de sementes foi de $320,40 \%$. Esses aumentos foram alcançados porque o fósforo contribuiu para aumentar o número de frutos, por cacho e por parcela, diminuir a porcentagem de casca no fruto e aumentar o peso de sementes por cacho. Dentre os cachos, os primários sempre reagiram melhor ao fósforo. Contribuiu também para elevar o teor do próprio fósforo nas sementes e uma tendência a diminuir o teor de nitrogênio nas cascas. O teor de óleo nas sementes não foi afetado pela adição de fósforo no solo.

\section{INTRODUÇÃO}

Os primeiros trabalhos de adubação em mamoneira, realizados no Estado de São Paulo, não apresentaram respostas definidas a determinado nutriente. Contudo, pesquisas mais recentes mostram que o fósforo é o fator principal no incremento da produção de mamona (CANECCHIO FILHO, ROCHA e FREIRE, 1963; SOUZA et al., 1974; NAGAGAWA, NEPTUNE e JAEHN, 1974) .

* Departamento de Ciências do Solo - FCMBB - Botucatu.

* Departamento de Solos e Geologia - ESALQ - USP - Piracicaba.

*** Bolsista do Conselho Nacional de Desenvolvimento Científico e Tecnológico - CNPq.

**** Seção de Fitoquímica - IAC — Campinas. 
Baseado neste último trabalho, onde se observou um nítido efeito do fósforo na produção de sementes da mamoneira, delineou-se um ensaio de campo, utilizando-se doses crescentes de fósforo, em Latossolo Vermelho Escuro - fase arenosa, para verificar os efeitos deste nutriente na produção de sementes, nos teores de óleo e de macronutrientes nas sementes e nos teores destes nutrientes também na casca do cultivar “Campinas'. O trabalho é pois a sequência de outras pesquisas sobre nutrição e adubação da mamoneira, desenvolvidas pelos autores, tendo até o presente momento momento estudado: marcha de absorção de nitrogênio, fósforo, potássio, cálcio e magnésio, nos cultivares 'Campinas' e 'IAC-38' (NAKAGAWA e NEPTUNE, 1971 e 1973); efeitos isolado e combinado de nitrogênio, fósforo e potássio na produção dos cultivares 'Campinas' e 'IAC-38' (NAKAGAWA, NEPTUNE e JAEHN, 1974) e, ainda, os efeitos de localização de adubos fosfatados e avaliação dos efeitos residuais dos fosfatos, no cultivar 'Campinas' (NAKAGAWA et al., 1975).

\section{MATERIAL E MÉTODOS}

O solo utilizado foi classificado, ao nível de reconhecimento por ESPINDOLA, TOSIN \& PACCOLA (1973), como sendo Latossolo Vermelho Escuro - fase arenosa, que representa de 15 a $20 \%$ dos siolos de São Paulo. A amostra de solo, retirada do local do ensaio, antes da sua instalação, revelou baixa fertilidade, conforme mostram os dados obtidos pela nálise química:

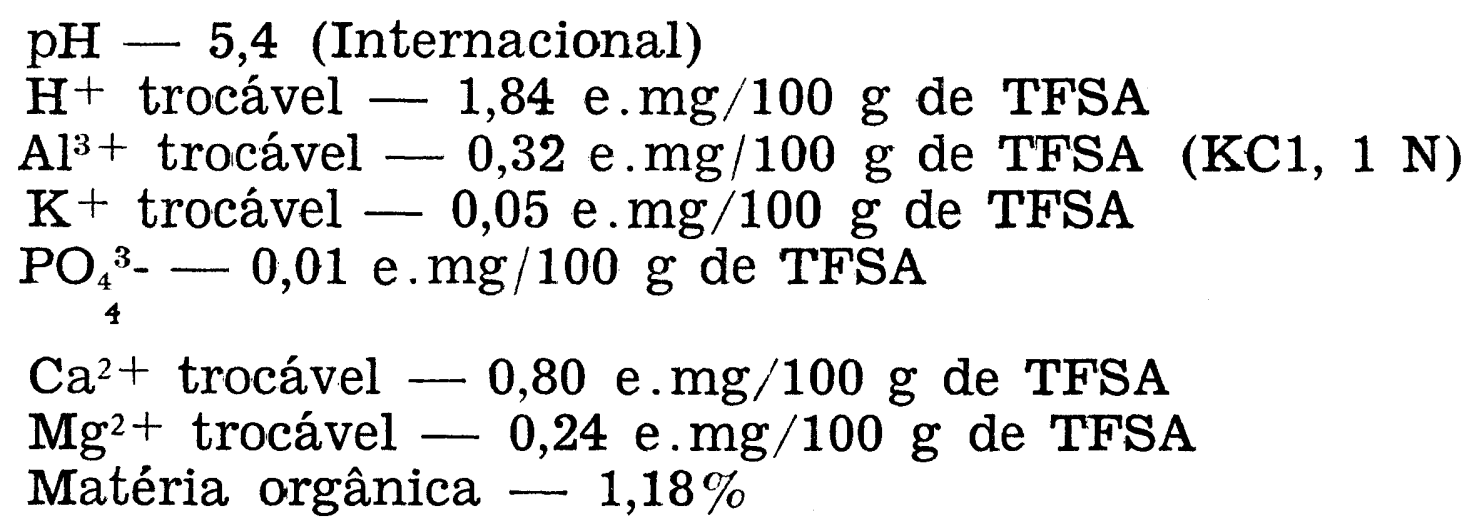

O hidrogênio trocável foi extraído com acetato de cálcio, solução neutra, e titulado com soda $0,02 \mathrm{~N}$; o potássio foi determinado por fotometria de chama após a extração com solução de $\mathrm{HNO}_{3} 0,05 \mathrm{~N}$; o fósforo por fotocolorimétria, tendo como extrator $\mathrm{o} \mathrm{H}_{2} \mathrm{SO}_{4} 0,05 \mathrm{~N}$. Todos esses métodos foram efetuados conforme descrito em CATANI, GALLO e GARGANTINI (1955) . A matéria orgânica foi determinada pelo método de Wakley e Black, modificado por MALAVOLTA \& COURY (1954), que consiste em titular o excesso de solução de bicromato de 
potássio com sulfato ferroso. Finalmente, o cálcio e o magnésio foram determinados pelo método do EDTA, desenvolvido por GLORIA, CATANI \& MATUO (1965).

O cultivar utilizado no presente estudo foi o 'Campinas', cuja descrição botânica consta em BANZATO \& ROCHA (1965). Trata-se de um cultivar de frutos indeiscentes e porte médio.

NAKAGAWA, NEPTUNE \& JAEHN (1974) verificaram que as doses 80 e $160 \mathrm{~kg} / \mathrm{ha}$ de $\mathrm{P}_{2} \mathrm{O}_{5}$ aumentaram a produção em 111,51 e $138,38 \%$, em relação à dose de $40 /$ ha de $\mathrm{P}_{2} \mathrm{O}_{5}$. Em função destes dados, foram utilizados as doses de 0-40-80-120-160 e $200 \mathrm{~kg} /$ ha de $\mathrm{P}_{2} \mathrm{O}_{5}$, que constituíram em tratamentos, repetidos cinco vezes cada. As doses de nutrogênio e $\mathrm{K}_{2} \mathrm{O}$ foram respectivamente 80 e $40 \mathrm{~kg} / \mathrm{ha}$, tendo-se parcelado o nitrogênio em duas aplicações, $30 \mathrm{~kg}$ no plantio e 50 $\mathrm{kg}$ em cobertura 50 dias após o plantio. O potássio e o fósforo foram aplicados no plantio, sendo as fontes cloreto de potássio e superfosfato simples respectivamente, enquanto o sulfato de amônio serviu de fonte nitrogenada.

As parcelas ocuparam $30 \mathrm{~m}^{2}$ (5 $\mathrm{m}$ de comprimento por $6 \mathrm{~m}$ de largura) comportando quatro linhas espaçadas entre si de $1,50 \mathrm{~m}$, e 40 plantas, sendo portanto a distância entre plantas na linha de $0,50 \mathrm{~m}$. $\mathrm{Na}$ colheita, entretanto, aproveitaram-se duas linhas centrais de oito plantas por linha, desprezando-se uma planta de cada extremidade da linha útil. Desta forma, foi colhida e avaliada uma população de dezesseis plntas por parcela.

Realizou-se a semeadura aos 27-10-1971, colocando-se três sementes por cova, desbastando-se, após 15 dias da germinação, para uma planta por cova. Assim procedendo obteve-se $100 \%$ no "stand".

Embora se tratasse de cultivar indeiscente, sem risco de perda de sementes por abertura de frutos, as colheitas se processaram conforme eles iam amadurecendo, a fim de evitar possíveis quedas dos frutos pela secagem excessiva. Em virtude disso, o início da colheita foi em fins de março e encerramento ocorreu em meados de julho.

Na colheita, eram contados números de cachos primários, secundários, terciários e restante. Dentro de cada cacho, fez-se o mesmo em relação ao número de frutos, obtendo-se assim, o número de frutos totais por parcela e por cacho. Os frutos eram pesados separadamente, em função do tipo de cacho, a $60^{\circ} \mathrm{C}$ para uniformização de umidade, até peso constante. Pesando-se cada parte, obteve-se peso de frutos por parcela e por cacho de cada uma das variações já citadas. 
De cada tipo de cacho, tomou-se amostra de $200 \mathrm{~g}$ e separou-se esta amostra em cascas e sementes. A pesagem destas duas partes permitiu a determinação da porcentagem de semente no fruto e, a partir desta valor, avaliou-se a produção de sementes em gramas por parcela, gramas por planta e, finalmente, $\mathrm{kg} / \mathrm{ha}$.

Nas sementes, foram determinados peso de 100 sementes (que devido ao seu número pode se fazer apenas com quatro repetições), os teores de óleo e de nitrogênio, fósforo, potássio, cálcio e magnésio, tendo estes nutrientes sido determinados também na casca.

A destilação de óleo nas sementes foi realizada em aparelho Soxhlet. $\mathrm{O} \mathbf{N}$ foi determinado em micro Kjeldahl, partindo-se do material digerido em solução sulfúrica (MALAVOLTA, 1965) . Para determinação de $\mathrm{P}, \mathrm{K}, \mathrm{Ca}$ e $\mathbf{M g}$, preparou-se extrato nítrico-perclórico, conforme descrito em LOTT et al . (1956) . Nesse extrato, o fósforo foi determinado em fotocolorímetro, Coleman $\mathrm{Jr}$., modelo 6/35; o potássio, cálcio e magnésio em espectrofotômetro de absorção atômica Perkin-Elmer, modelo 302-B.

As análises estatísticas foram realizadas com o auxílio de computador do Departamento de Matemática e Estatística da Faculdade de Ciências Médicas e Biológicas de Botucatu, tendo-se transformado os dados originais de porcentagens de valores pequenos em arc sen $\%$.

\section{RESULTADOS}

As médias dos resultados obtidos, devidamente interpretados, segue nos Quadros 1 a 10.

Para melhor compreensão desses Quadros, deve-se observar que:

- letras diferentes na mesma coluna significam que as médias diferem entre si;

- quando não aparecem letras na coluna, os tratamentos não diferiram entre si.

Os dados do Quadro 1 representam peso de sementes, calculado a partir da produção de frutos no Quadro 2 e porcentagem de sementes nos frutos do Quadro 4. Por se tratar de estimativa preferiu-se não efetuar a análise de variância. 
QUADRO I - Produção de sementes, em $\mathrm{kg}$ por ha, de cachos primários, secundários, terciários, restantes e totais do cultivar 'Campinas'. Média de cinco repetições.

\begin{tabular}{|c|c|c|c|c|c|}
\hline \multirow{2}{*}{$\begin{array}{l}\mathrm{kg} / \mathrm{ha} \\
\mathrm{P}_{2} \mathrm{O}_{5}\end{array}$} & \multicolumn{5}{|c|}{$\mathrm{CACHOS}$} \\
\hline & PRIMÁRIOS & SECUNDÁRIOS & TERCIÁRIOS & RESTANTES & TOTAIS \\
\hline 0 & 227,46 & 141,67 & 100,00 & - & 483,33 \\
\hline 40 & 529,55 & 383,33 & 408,33 & 300,00 & $1.616,66$ \\
\hline 80 & 679,78 & 475,00 & 566,67 & 370,83 & $2.094,16$ \\
\hline 120 & 700,00 & 409,16 & 548,33 & 282,54 & $1.945,83$ \\
\hline 160 & 841,66 & 410,83 & 503,33 & 358,33 & $2.116,66$ \\
\hline $2(x)$ & 783,33 & 510,00 & 588,33 & 504,16 & $2.386,66$ \\
\hline
\end{tabular}

QUADRO II - Produção de frutos, em g por parcela, de cachos primários, secundários, terciários, restantes e totais do cultivar 'Campinas'. Média de cinco repetições.

\begin{tabular}{|c|c|c|c|c|c|}
\hline \multirow{2}{*}{$\begin{array}{l}\mathrm{kg} / \mathrm{ha} \\
\mathrm{P}_{2} \mathrm{O}_{5}\end{array}$} & \multicolumn{5}{|c|}{$\mathrm{CACHOS}$} \\
\hline & PRIMÁRIOS & SECUNDÁRIOS & TERCIÁRIOS & RESTANTES & TOTAIS \\
\hline 0 & $411,95 \mathrm{a}$ & $245,10 \mathrm{a}$ & $178,53 *$ & - & $835,58 \mathrm{a}$ \\
\hline 4) & 892,89 ab & $640,99 \mathrm{~b}$ & 685,41 & 685,41 & $2.712,47 \mathrm{~b}$ \\
\hline 80 & $1.125,62 \mathrm{~b}$ & $781,73 \mathrm{~b}$ & 949,06 & 604,28 & $3.460,70 \mathrm{~b}$ \\
\hline 120 & $1.161,62 \mathrm{~b}$ & $695,20 \mathrm{~b}$ & 929,98 & 455,40 & $3.242,21 \mathrm{~b}$ \\
\hline 160 & $1.401,62 \mathrm{~b}$ & $683,95 \mathrm{~b}$ & 836,66 & 593,25 & $3.515,48 \mathrm{~b}$ \\
\hline 200 & $1.302,69 \mathrm{~b}$ & $837,34 \mathrm{~b}$ & 983,15 & 817,86 & $3.941,04 \mathrm{~b}$ \\
\hline $\begin{array}{l}\operatorname{dms}(5 \% \\
\text { ('Tukey) }\end{array}$ & $\begin{array}{l}\text { y) } \\
\text { y) }\end{array}$ & 348,54 & 684,59 & 678,90 & $1.462,37$ \\
\hline C.V.\% & 24,69 & 39,30 & 39,30 & 57,65 & 24,58 \\
\hline
\end{tabular}

* Tratamento não considerado na análise de variância, por falta de produções em algumas repetições. 
QUADRO III - Número de frutos, obtidos por parcela, de cachos primários, secundários, terciários, restantes e totais do cultivar 'Campinas'. Média de cinco repetições.

\begin{tabular}{cccccr}
\hline $\mathrm{kg} / \mathrm{ha}$ & \multicolumn{5}{c}{$\mathrm{CA} C \mathrm{C}$ O S } \\
\cline { 2 - 6 } $\mathrm{P}_{2} \mathrm{O}_{5}$ & PRIMARIOS & SECUNDARIOS & TERCIARIOS & RESTANTES & TOTAIS \\
\hline 0 & $239,8 \mathrm{a}$ & $153,4 \mathrm{a}$ & $107,0 *$ & - & $500,2 \mathrm{a}$ \\
40 & $561,2 \mathrm{~b}$ & $424,6 \mathrm{~b}$ & 453,8 & 305,4 & $1.745,0 \mathrm{~b}$ \\
80 & $621,0 \mathrm{~b}$ & $489,2 \mathrm{~b}$ & 603,0 & 342,0 & $2.055,2 \mathrm{~b}$ \\
120 & $669,8 \mathrm{~b}$ & $466,0 \mathrm{~b}$ & 570,4 & 252,0 & $1.958,2 \mathrm{~b}$ \\
160 & $769,2 \mathrm{~b}$ & $459,2 \mathrm{~b}$ & 539,8 & 337,2 & $2.105,4 \mathrm{~b}$ \\
200 & $733,0 \mathrm{~b}$ & $546,6 \mathrm{~b}$ & 644,6 & 441,4 & $2.365,6 \mathrm{~b}$ \\
Dms $(5 \%)$ & 285,5 & 190,6 & 235,27 & 328,18 & 779,8 \\
$($ Tukey) & & & & & \\
C.V.\% & 23,95 & 22,64 & 21,06 & 49,22 & 21,91 \\
\hline
\end{tabular}

* Tratamento não considerado na análise de variância, por falta de produções em algumas repetições.

QUAJRO IV - Porcentagem de sementes do peso de frutos de cachos primários, secundários, terciários, restantes e médias dos totais do cultivar 'Campinas'. Média de cinco repetições.

\begin{tabular}{|c|c|c|c|c|c|}
\hline \multirow{3}{*}{$\begin{array}{l}\mathrm{kg} / \mathrm{ha} \\
\mathrm{P}_{2} \mathrm{O}_{3}\end{array}$} & \multicolumn{5}{|c|}{$\mathrm{CACHOS}$} \\
\hline & \multirow[b]{2}{*}{ PRIMÁRIOS } & \multirow[b]{2}{*}{ SECUNIARIOS } & \multirow[b]{2}{*}{ TERCIARIOS } & \multirow[b]{2}{*}{ RESTANTES } & \multirow{2}{*}{$\begin{array}{c}\text { MEDIAS } \\
\text { DOS } \\
\text { TOLAIS }\end{array}$} \\
\hline & & & & & \\
\hline 0 & $66,26 \mathrm{a}$ & 70,50 & $69,84 *$ & - & $71,40 \mathrm{~b}$ \\
\hline 40 & $71,17 \mathrm{ab}$ & 71,00 & 70,77 & 70,69 & $68,84 \mathrm{a}$ \\
\hline 80 & $72,47 \mathrm{~b}$ & 72,90 & 71,49 & 73,60 & $72,61 \mathrm{~b}$ \\
\hline 120 & $72,21 \mathrm{~b}$ & 70,64 & 70,76 & 74,45 & $72,00 \mathrm{~b}$ \\
\hline 160 & $72,12 \mathrm{~b}$ & 72,03 & 72,17 & 72,48 & $72,23 \mathrm{~b}$ \\
\hline 200 & $71.88 \mathrm{~b}$ & 73,04 & 71,81 & 73,91 & $72,65 \mathrm{~b}$ \\
\hline $\begin{array}{l}\text { Dms }(50 \\
\text { (Tukey }\end{array}$ & $\begin{array}{l}\%) \\
\text { y) }\end{array}$ & 4,97 & 3.75 & 2,90 & 2,71 \\
\hline C.V. & $\% \quad 3,51$ & 3,49 & 2,64 & 1,99 & 1,90 \\
\hline
\end{tabular}

* Tratamento não considerado na análise da variância, por falta de produções em algumas repetições. 
QUADRO V - Produção de sementes, em g por cachos, de cachos primários, secundários, terciários e restantes do cultivar 'Campinas'. Média de cinco repetições.

\section{A C H O S}

\begin{tabular}{cccccc}
$\begin{array}{c}\mathrm{kg} / \mathrm{ha} \\
\mathrm{P}_{2} \mathrm{O}_{5}\end{array}$ & PRIMÁRIOS & SECUNDARIOS & TERCIÁRIOS & RESTANTES & $\begin{array}{c}\text { MÉDIA } \\
\text { CACHO }\end{array}$ \\
\hline 0 & $28,87 \mathrm{a}$ & $25,99 \mathrm{a}$ & $22,84 *$ & - & $27,17 \mathrm{a}$ \\
40 & $57,50 \mathrm{a}$ & $42,76 \mathrm{ab}$ & 49,84 & $24,09 \mathrm{ab}$ & $42,93 \mathrm{ab}$ \\
80 & $69,27 \mathrm{bc}$ & $55,48 \mathrm{~b}$ & 61,83 & $23,93 \mathrm{ab}$ & $49,09 \mathrm{bc}$ \\
120 & $75,70 \mathrm{bc}$ & $46,68 \mathrm{~b}$ & 65,17 & $21,62 \mathrm{a}$ & $50,84 \mathrm{bc}$ \\
160 & $93,64 \mathrm{c}$ & $44,57 \mathrm{ab}$ & 60,88 & $25,55 \mathrm{ab}$ & $62,75 \mathrm{c}$ \\
200 & $83,09 \mathrm{bc}$ & $53,68 \mathrm{~b}$ & 65,68 & $29,72 \mathrm{~b}$ & $53,82 \mathrm{bc}$ \\
Dms(5\%) 27,84 & 19,68 & 16,85 & 7,80 & 16,98 \\
$($ Tulkey) & & & & 15,79 & 18,52 \\
C.V.\% 20,57 & 22,38 & 13,98 & & &
\end{tabular}

* Tratamento não considerado na análise de variância, por falta de produções em algumas repetições.

QUADRO VI - Número de frutos por cachos primários, secundários, terciários e restantes do cultivar 'Campinas'. Média de cinco repetições.

\begin{tabular}{|c|c|c|c|c|c|}
\hline \multirow[b]{2}{*}{$\begin{array}{l}\mathrm{kg} / \mathrm{ha} \\
\mathrm{P}_{2} \mathrm{O}_{5}\end{array}$} & \multicolumn{5}{|c|}{$\mathrm{CACHOS}$} \\
\hline & PRIMARIOS & SECUNDARIOS & TERCIARIOS & RESTANTES & $\begin{array}{l}\text { MEDIA/ } \\
\text { CACHO }\end{array}$ \\
\hline 0 & $17,32 \mathrm{a}$ & $16,52 \mathrm{a}$ & $21,40 *$ & - & $16,98 \mathrm{a}$ \\
\hline 40 & $36,23 \mathrm{~b}$ & $28,26 \mathrm{~b}$ & 33,20 & 16,20 & $27,92 \mathrm{~b}$ \\
\hline 80 & $38,13 \mathrm{bc}$ & $32,33 \mathrm{~b}$ & 39,34 & 14,41 & $29,29 \mathrm{~b}$ \\
\hline 120 & $43,73 \mathrm{bc}$ & $31,32 \mathrm{~b}$ & 40,18 & 12,86 & $30,96 \mathrm{~b}$ \\
\hline 160 & $51,34 \mathrm{c}$ & $30,41 \mathrm{~b}$ & 39,41 & 15,62 & $31,66 \mathrm{~b}$ \\
\hline 200 & $46,74 \mathrm{bc}$ & $35,04 \mathrm{~b}$ & 43,08 & 17,78 & $32,54 \mathrm{~b}$ \\
\hline $\begin{array}{l}\operatorname{Dms}(5 \% \\
\text { (Tukey }\end{array}$ & $\begin{array}{l}\%) \quad 14,91 \\
\text { y) }\end{array}$ & 10,25 & 9,82 & 5,04 & 9,69 \\
\hline C.V. \% & $\% \quad 19,25$ & 17,79 & 12,66 & 16,52 & 17,26 \\
\hline
\end{tabular}

* Tratamento não considerado na análise de variância, por falta de produções em algumas repetições. 
QUADRO VII - Peso de 100 sementes, em g, de cachos primários, secundários, terciários e restanttes do cultivar 'Campinas'. Média de cinco repetições.

\begin{tabular}{ccccc}
\hline $\mathrm{kg} / \mathrm{ha}$ & \multicolumn{5}{c}{$\mathrm{C} \mathrm{A} \mathrm{C} \mathrm{H} \mathrm{O} \mathrm{S}$} \\
\cline { 2 - 5 } $\mathrm{P}_{2} \mathrm{O}_{5}$ & PRIMÁRIOS & SECUNDRIOS & TERCIARIOS & RESTANTES \\
\hline \hline 0 & $29,96 \mathrm{a}$ & $30,41 \mathrm{a}$ & - & - \\
40 & $34,74 \mathrm{ab}$ & $34,24 \mathrm{ab}$ & 39,00 & 36,17 \\
80 & $40,66 \mathrm{c}$ & $38,70 \mathrm{~b}$ & 38,76 & 39,24 \\
120 & $39,64 \mathrm{bc}$ & $34,51 \mathrm{ab}$ & 38,35 & 39,97 \\
160 & $43,98 \mathrm{c}$ & $38,04 \mathrm{ab}$ & 37,00 & 39,10 \\
200 & $42,08 \mathrm{c}$ & $35,88 \mathrm{ab}$ & 38,80 & 36,91 \\
Dms $(5 \%)$ & 5,31 & 8,12 & 4,32 & 8,06 \\
$($ Tukey) & & & & 10,60 \\
C.V. \% & 6,93 & 11,56 & 5,66 & \\
\hline
\end{tabular}




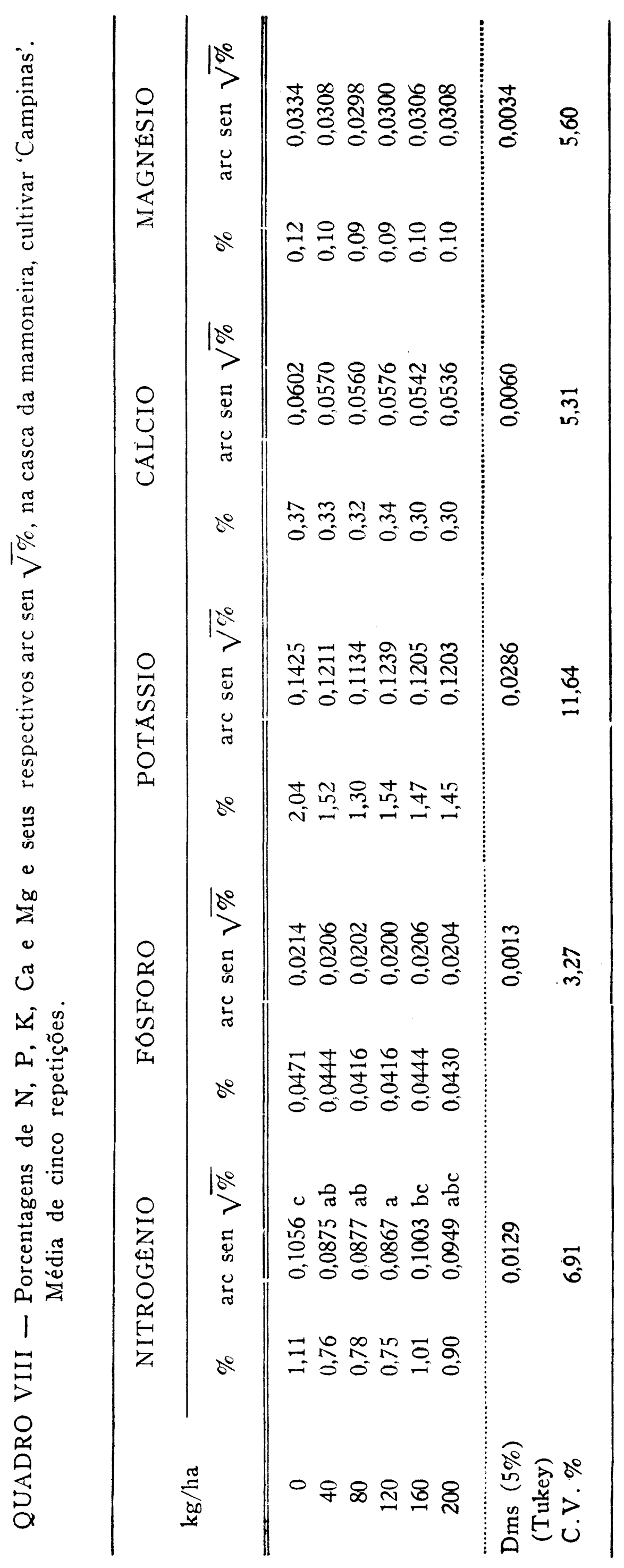




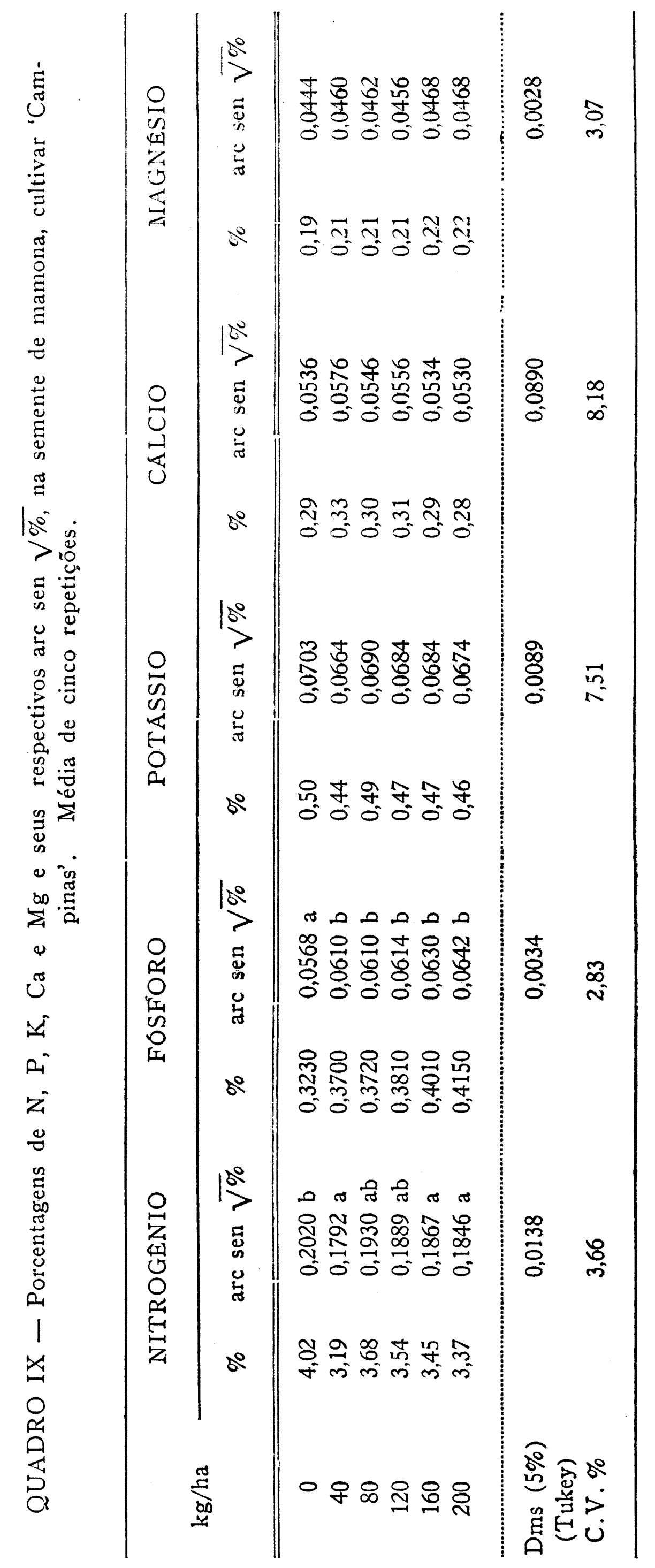




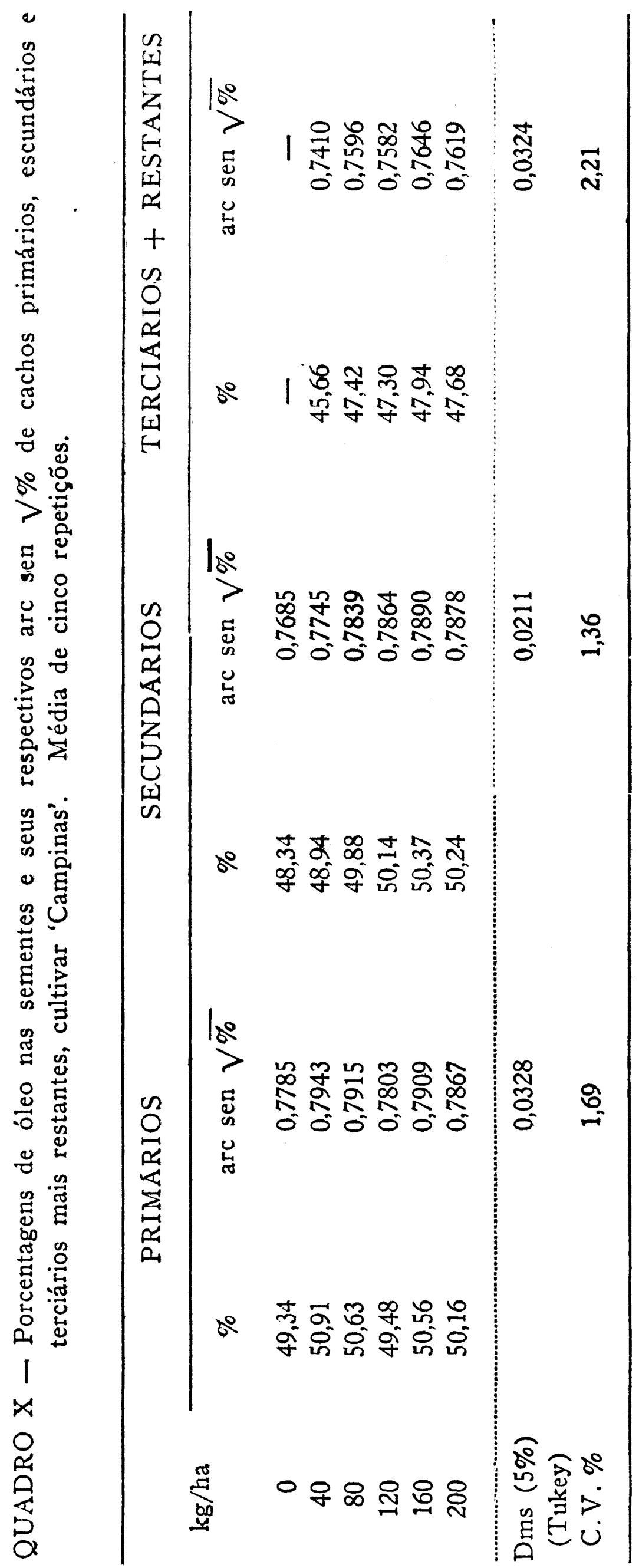




\section{DISCUSSÃO}

Como se verificou também em trabalhos anteriores, realizados por vários autores, CANECCHIO FILHO, ROCHA \& FREIRE (1963), SOUZA et al. (1974), ANDEOLI (1974) e NAKAGAWA, NEPTUNE \& JAEHN (1974), o fósforo incrementou significativamente a produção de sementes. Pelos dados do Quadro 1, observa-se que o fósforo afetou grandemente a produção dos cachos primários, secundários, terciários e restantes. As proporções dos aumentos verificados na produção total, em relação à testemunha, foram $234,48 \%, 333,28 \%, 302,59 \%$, $337,93 \%$ e $393,73 \%$, respectivamente, para as doses de 40, 80, 120, 160 e $200 \mathrm{~kg}$, por ha, de $\mathrm{P}_{2} \mathrm{O}_{5}$.

Os dados da produção total, em peso de frutos por parcela, do Quadro 2, mostram, contudo, que estatisticamente só houve diferença singnificativa entre a testemunha e os tratamentos com fósforo. Dentro de cada tipo de cacho, apenas o cacho primário mostrou maior necessidade de fósforo, pois a produção resultante da aplicação de $40 \mathrm{~kg}$, por ha, (dose um) colocou-se na posição intermediária, não diferindo nem das produções de outros tratamentos, inclusive naquele em que se forneceu a maior dose, e nem da testemunha sem fósforo. As diferenças cada vez mais acentuadas, entre as produções dos tratamentos com e sem fósforo, verificadas nos cachos secundários, terciários e restantes, contribuíram para que, na produção total, desaparecesse a situação intermediária nos cachos primários.

Situação semelhante ocorreu com o total do número de frutos, isto é, a produção da testemunha foi significativamente menor do que as produções dos tratamentos adubados. A única diferença observada é que não existiu a posição intermediária na produção do número de frutos na dose de $40 \mathrm{~kg}$ de $\mathrm{P}_{2} \mathrm{O}_{5}$ (Quadro 3), no cacho primário. Este resultado mostra que o fósforo afetou mais a produção do número de frutos do que o peso destes.

Em relação à porcentagem de peso das sementes nos frutos, os resultados mostraram que os pesos de frutos dependem grandemente da quantidade inicial de fósforo no solo, uma vez que apenas nos cachos primários as diferenças foram significativas entre testemunha e as doses acima de $80 \mathrm{~kg}$, por ha, de $\mathrm{P}_{2} \mathrm{O}_{5}$. A amostra proveniente da "mistura" de todos os tipos de cacho, que figura na coluna dos totais do Quadro 4, revela que a diferença ocorreu apenas entre os tratamentos adubados e não adubados. E fácil de se compreender esse resultado. A presença de frutos dos cachos secundários, terciários e restantes na "mistura" diluiu o efeito do fósforo, como se verificou na produção de frutos dos cachos primários. NAKAGAWA, NEPTUNE \& JAEHN (1974) verificaram que os efeitos de doses de $\mathrm{N}, \mathrm{P}$ e $\mathrm{K}$ se faziam sen- 
tir apenas na produção dos frutos e não de seus componentes (casca. e sementes), contrariando, portanto, este resultado. O que ocorreu naquele trabalho se deve a problema de dose inicial de $40 \mathrm{~kg}$ de $\mathrm{P}_{2} \mathrm{O}_{5}$ por há, justamente onde se verificou neste trabalho o feito, isto é, do zero para a dose de $40 \mathrm{~kg}$ de fósforo.

A produção de sementes, em gramas por cacho, (Quadro 5) foi também influenciada pela adubação fosfatada, principalmente, nos cachos primários, secundários e totais. Os cachos primários apresentaram uma produção crescente até a dose de $160 \mathrm{~kg}$ por ha, decaindo a seguir. Nos cachos secundários, a diferença mais acentuada foi entre os tratamentos adubados e o não adubado.

Os dados de produção de frutos por cacho (Quadro 6) apresentam resultados estatísticos bastante semelhantes aos do Quadro 5, quanto aos cachos primários, secundários, terciários e restantes. Os valores dos totais, porém, mostram que a menor dose foi suficiente para aumentar o número de frutos, em termos equivalentes aos aumentos verificados com a aplicação de maiores doses de fósforo.

Um fato intrigante observado foi que, em todos os parâmetros vistos até agora, os cachos secundários produziram menos do que os cachos terciários, o que parece uma incoerência, do ponto de vista biológico da cultura. A frutificação dos cachos secundários se verifica em torno de 100 dias, após a germinação, que, no caso, ocorreu no mês de fevereiro, quando a precipitação mensal foi de $281,9 \mathrm{~mm}$. Segundo Jarry, citado por EL BARADI (1969) a umidade atmosférica muito alta prejudica a frutificação, pela redução do poder germinativo do pólem. Provavelmente isto deve ter-se verificado neste ensaio.

Dentro de cada tratamento, as Figuras 1 a 6, expressas em porcentagem do peso de sementes, mostram que, em qualquer circunstância, a produção dos cachos primários é decisava no incremento da produção. Essa contribuição dos cachos primários torna-se menor, porém, tanto em peso como em número de frutos, quando o teor no solo é baixo (Figuras 1 e 7). Nota-se ainda que $160 \mathrm{~kg}$ por ha de $\mathrm{P}_{2} \mathrm{O}_{5}$ acentuaram a contribuição dos cachos primários na produção global. No tocante à distribuição percentual do número de frutos, as Figuras 7 a 12 revelam aspectos um pouco diferentes em relação aos do peso de frutos (Figuras 1 a 6). As maiores contribuições do cachos primários, na produção de número de frutos, por planta, foram nas doses de 120 e $160 \mathrm{~kg}$, por ha, de $\mathrm{P}_{2} \mathrm{O}_{5}$. A medida que se adiciona fósforo no solo, dentro de certos limites, a contribuição dos cachos primários aumenta percentualmente. Os dados são bem diferentes dos relatados por BANZATTO \& ROCHA (1965), que acharam maior contribuição dos cachos secundários, na produção global.

O confronto das Figuras, correspondentes às distribuições percentuais de peso de sementes e número de frutos dos cachos na planta, faz crer que, nas doses menores, o fósforo influi mais na formação do 


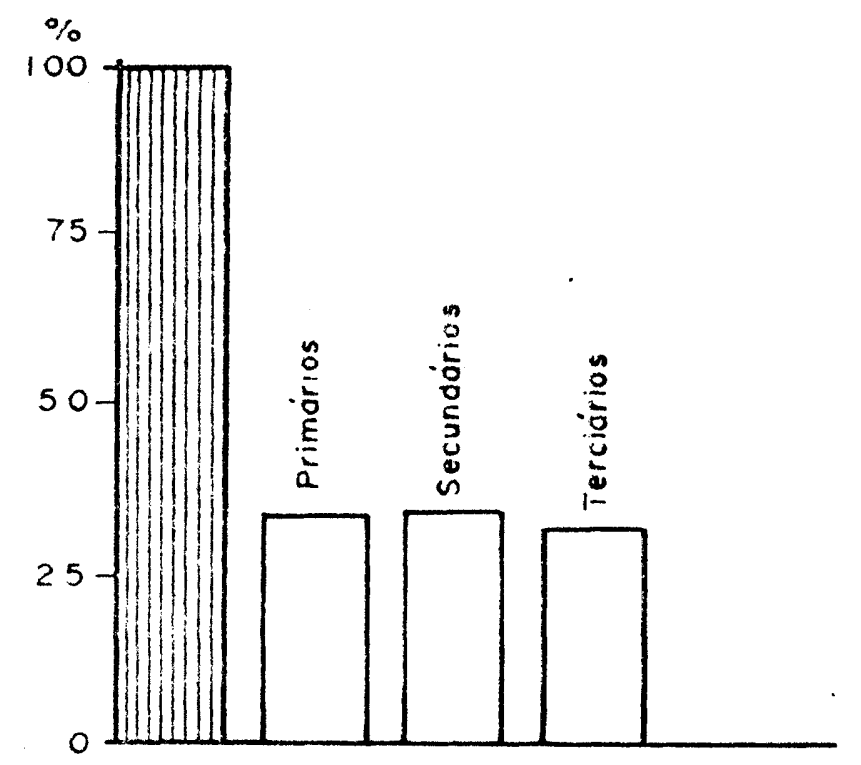

FlG 1 - Distribuicão percentual em peso, no tratamento 0 , cultivar "Campinas" por planta

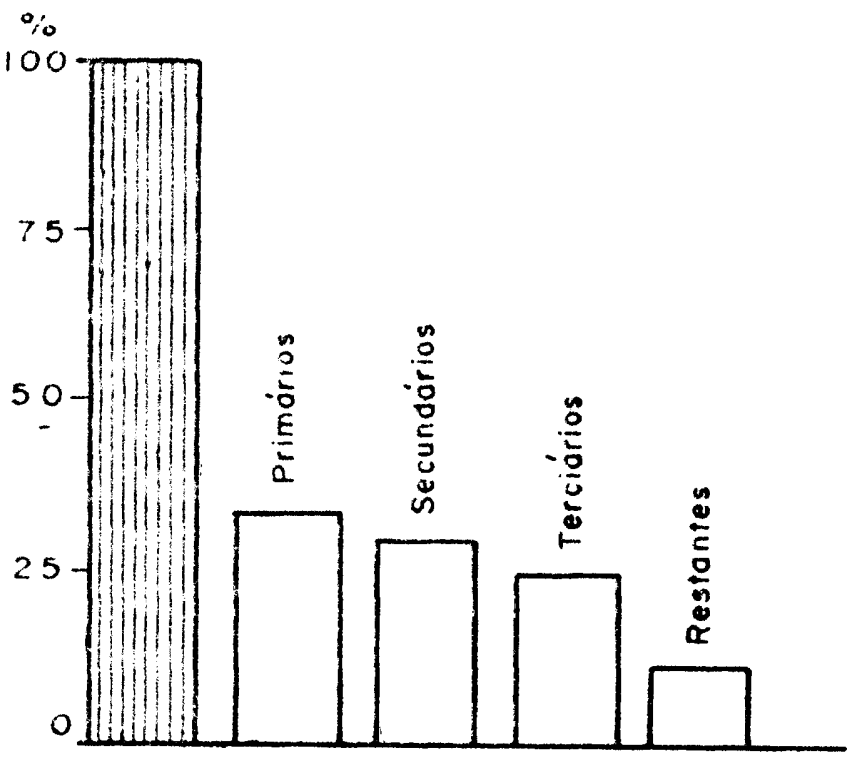

FIG.3- Distribuiçáo percentual em peso, no trata mento 80 , cultivar "Campinas" por planta

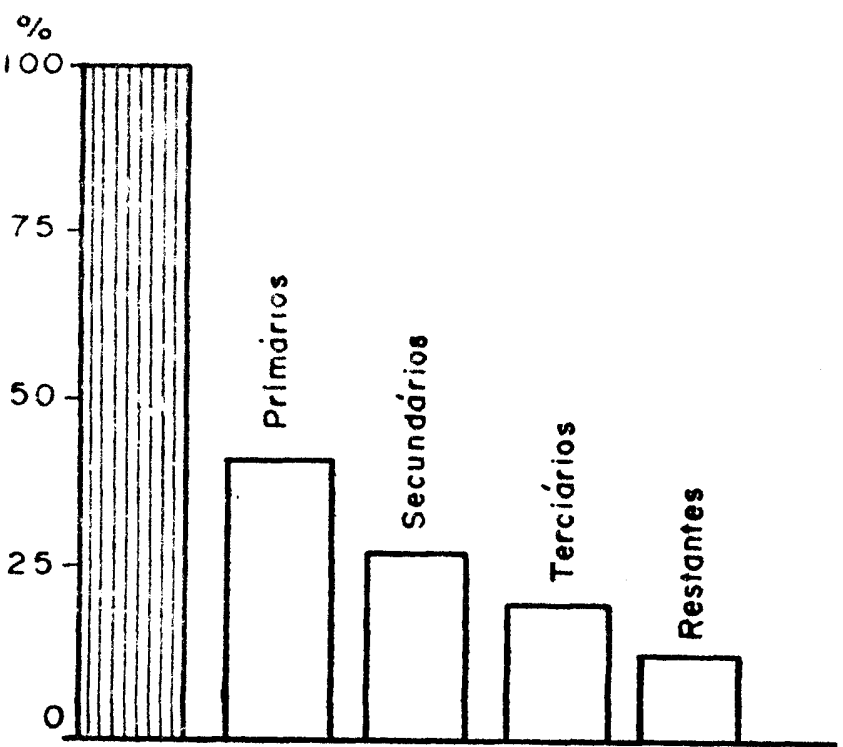

FIG. 5 - Distribuiçäo percentual em peso, no trafamento 160 , cultivar "Campinas" por planta

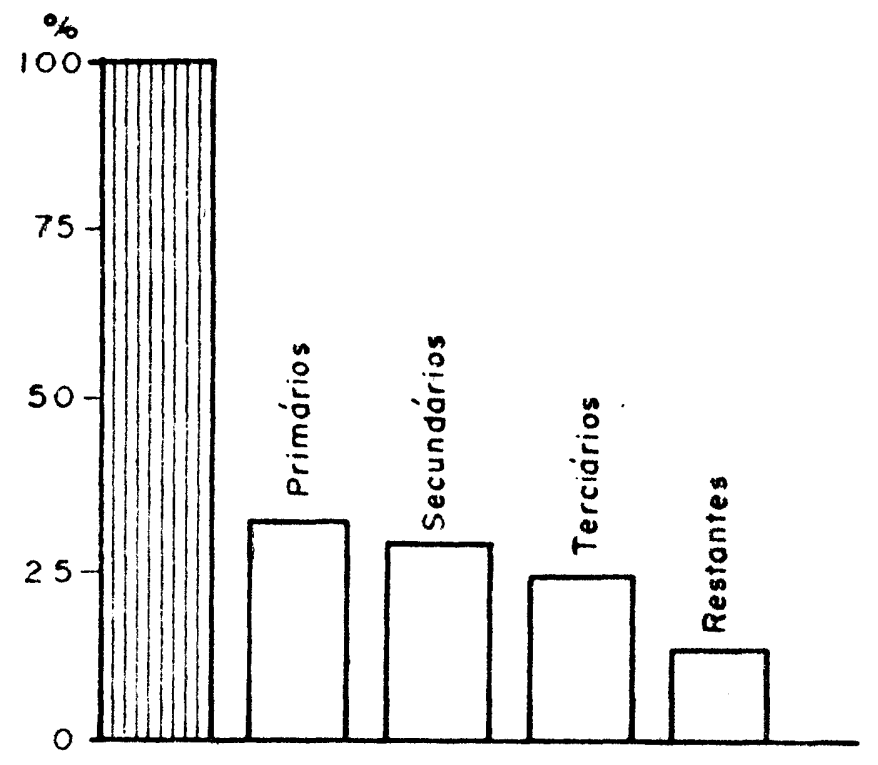

FIG 2 - Distribuição percenfual em peso, no tratamento 40, cultivar "Campinas" por plania

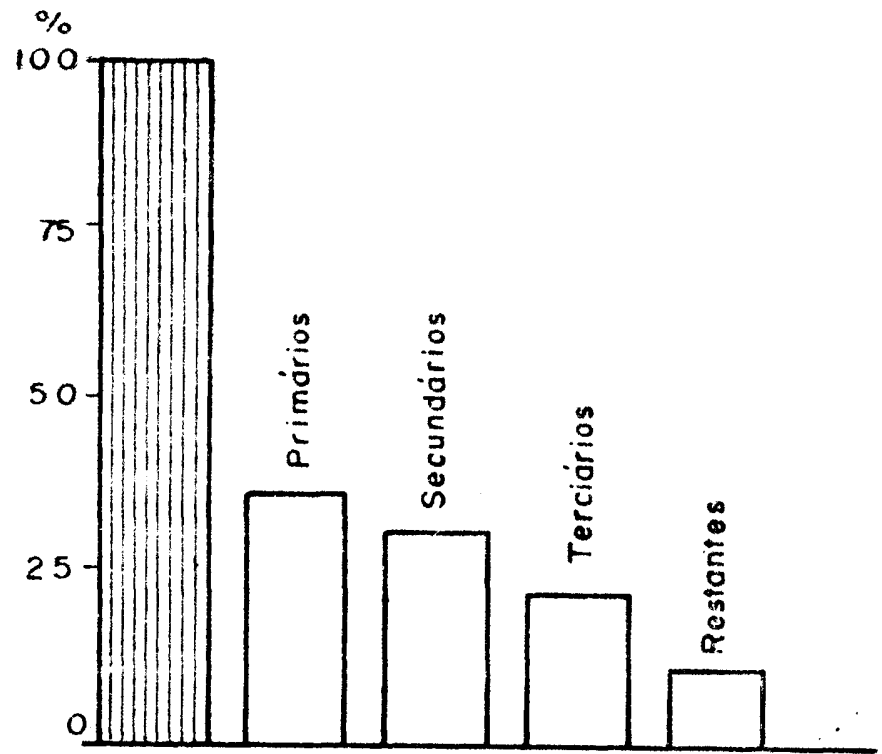

FIG 4-Distribuiçōo percentual em peso, no tratamento 120, cultivar "Campinas" por planta

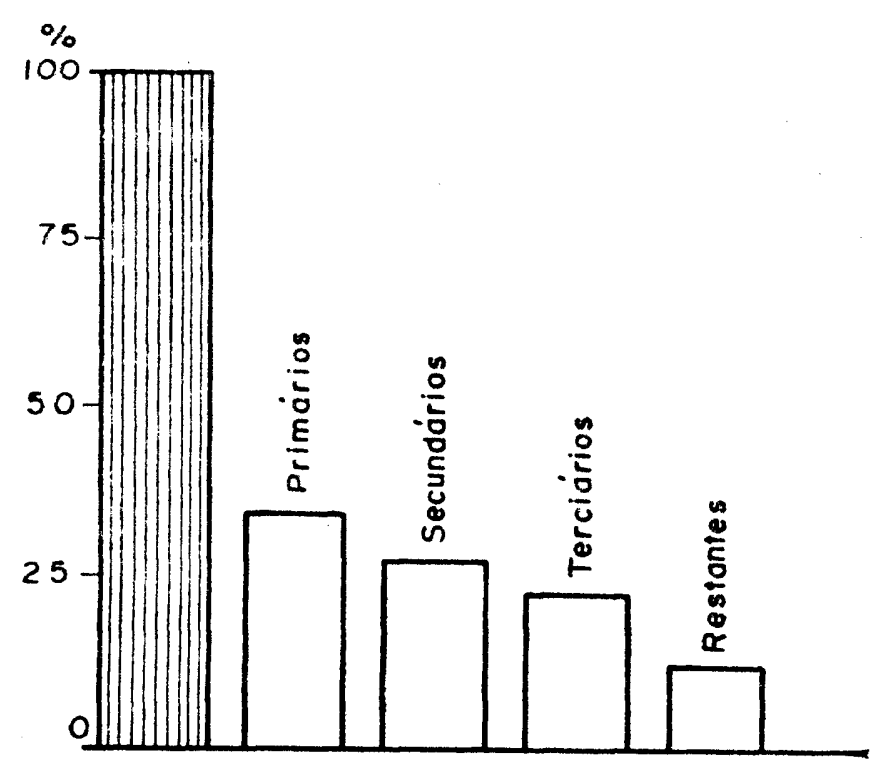

FIG.6 - Distribuiçőo percentual em peso, no trata mento 200, cultivar por planto 


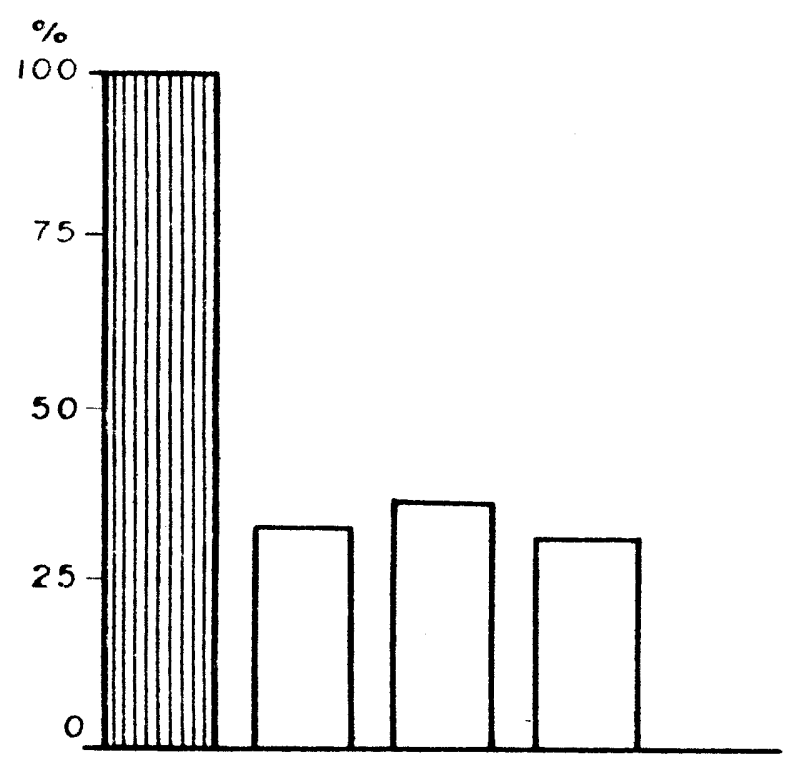

FIG. 7 - Distribuiçăo percentual em $n$ ? de frutos, no tratamento 0 , cultivar "Campinas", por planta

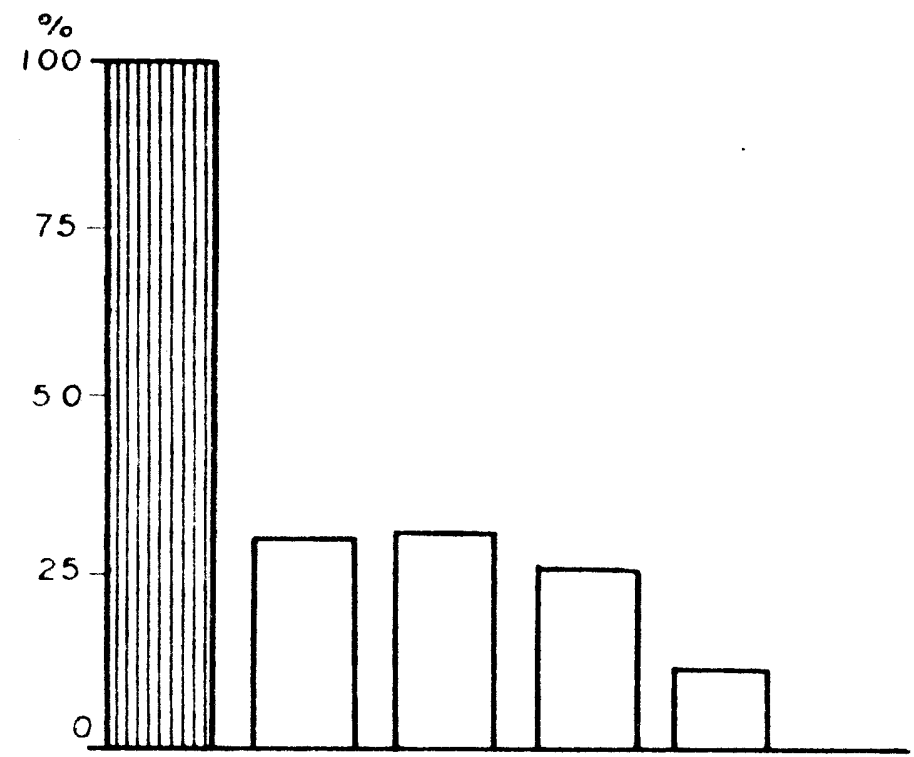

FIG. 9 - Distribuição percentual em no defrutos, no tratomento 80, cultivar "Campinos" por plantos

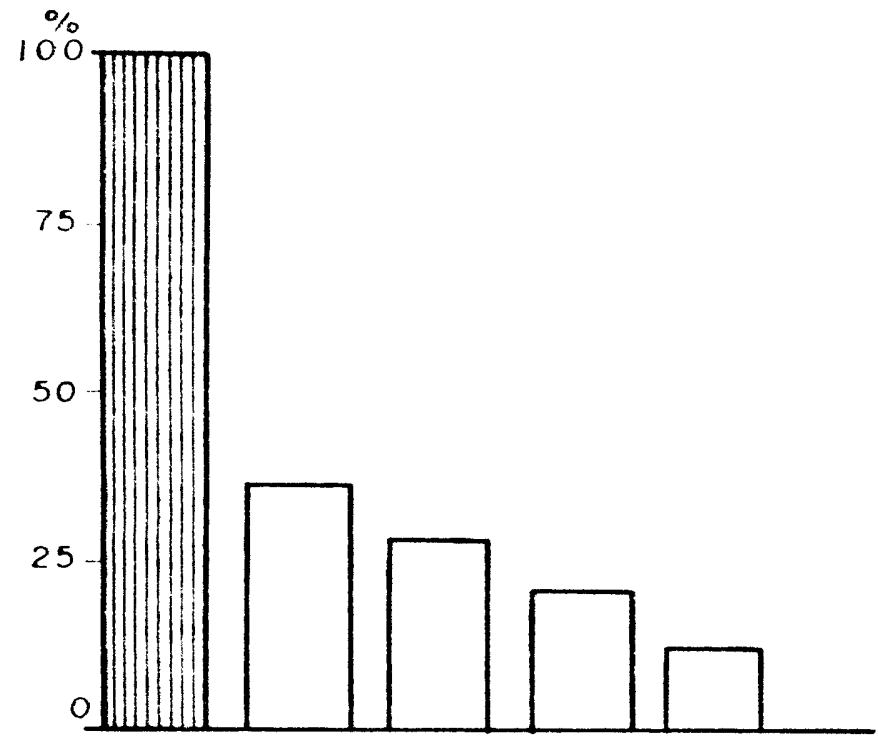

FIG. 11 -Distribuiçäo percentual em no de frutos, no tratamento 160, cultivor "Compinas" por planto

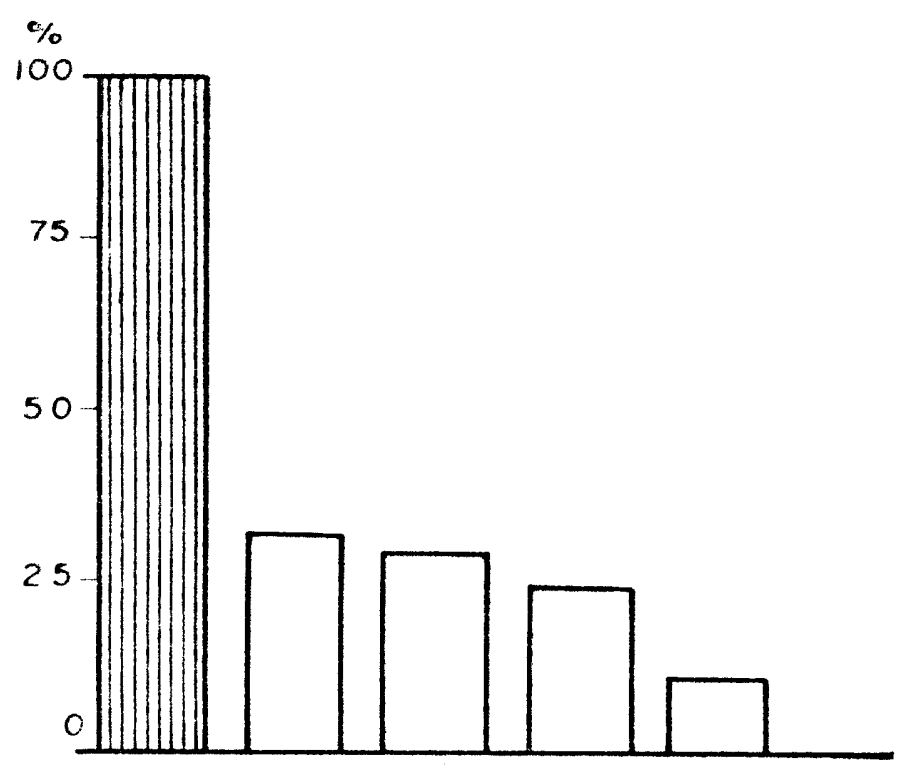

FIG.8-Distribuiçōo percentual em no de frutos, no tratomento 40, cultivar "Campinas", por planto

$\%$

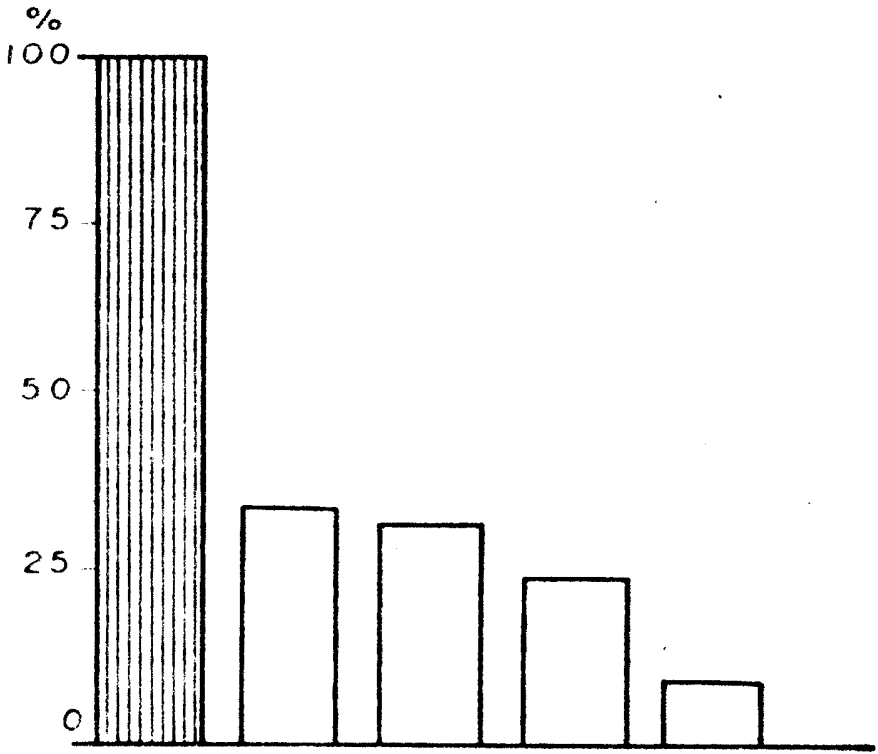

FIG 10-Distribuiçäo percentual em no de frutos, no tratamento 120, cultivar "Campinas" por planta

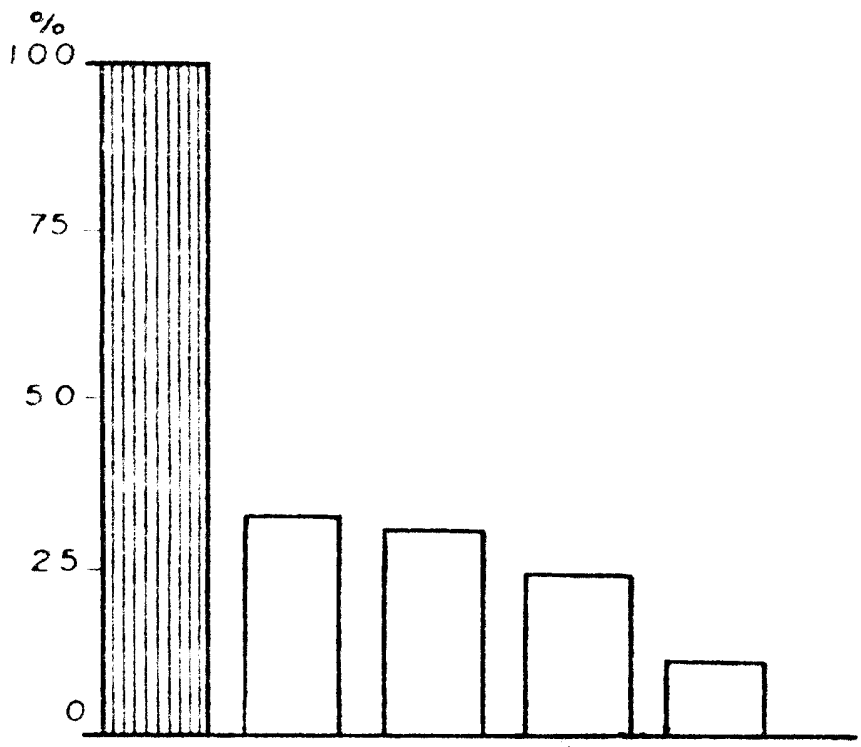

FIG 12- Distrit uiçáo percentual em no de frutos, no trotamento 200, cultivar "Campinas"por planto 
número de frutos, e à medida que se eleva a sua quantidade, ele começa a atuar também no peso das sementets. Nas doses ainda maiores, o efeito do fósforo se distribui, de uma forma praticamente equivalente, sobre o número e peso dos frutos.

Confrontando-se, entretanto, os dados do peso de sementes de um cacho (coluna dos totais do Quadro 5) com os dados do número de frutos por cacho do Quadro 6, pode-se deduzir que o efeito do fósforo sobre a produção de números de frutos é mais notório, uma vez que, enquanto os valores de peso de sementes cresceu até a dose de $160 \mathrm{~kg}$, por ha, de $\mathrm{P}_{2} \mathrm{O}_{5}$ e decresceu, na última dose, os valores do número de frutos tenderam para linearidade. Isto confirma o que se verificou no Quadro 3, na produção total de número de frutos, por parcela.

O Quadro 7, por sua vez, mostra que o peso de 100 sementes também é favorecido pela ação do fósforo. O quadro estatístico se configura bastante complexo, ora elevando-se, ora abaixando-se, em função da dose do fósforo adicionado ao solo, sem um comportamento definido. Verificando-se o Quadro 10, onde são apresentados os teores de óleo na semente, observa-se um teor maior de óleo nas sementes dos dois primeiros cachos. Segundo GURGEL \& VALSECHI (1952), existe boa correlação entre o tamanho das sementes com o peso de 100 sementes e com o teor de ôleo. Disto pode-se inferir que, no presente caso, o fósforo influi no tamanho das sementes dos dois primeiros cachos, contribuindo para aumentar o peso de 100 sementes e o seu teor de óleo.

Os dados obtidos evidenciam que o fósforo apresentou atuação mais prolongada na produção do número de frutos do que no peso de sementes, uma vez que o peso de 100 sementes (Quadro 7) caiu sensivelmente em função dos tipos de cachos. Outro aspecto verificado foi que a produção de sementes acompanhou a produção de frutos porque a porcentagem da semente no fruto praticamente se manteve em função dos diferentes tipos de cacho.

A casca dos frutos da mamoneira representa cerca de $30 \%$ do total da produpção e normalmente é empregado como material orgânico nas propriedades produtoras. Nas análises químicas de nutrientes, tabelados no Quadro 8, o nitrogênio variou significativamente entre alguns tratamentos, mas, pelos resultados, fica claro que as flutuações observadas independem das doses de fósforo acarreta uma tendência à diminuição nos teores de potássio, cálcio e magnésio, e até mesmo no teor do próprio fósforo. Comparando esses dados com os obtidos por NAKAGAWA \& NEPTUNE (1971) para o mesmo cultivar, pode-se dizer que peqenas diferenças foram encontradas nos teores de magnésio, principalmente. Contudo, é compreensível, pois, naquele trabalho, houve incorporação de calcário dolomítico. 
A análise química das sementes (Quadro 9) revelou que o nitrogênio foi favorecido na ausência de fósforo e este, ao contrário da casca, incrementou o seu teor, significativamente maior, em relação à testemunha. Nos demais nutrientes, não ocorreu nenhuma interferência, prevalecendo, todavia, o mesmo fato observado, na casca, para o potássio. Os resultados obtidos, praticamente conferem com os determinados por NAKAGAWA \& NEPTUNE (1971) para o cultivar 'Campinas', exceto no caso do potássio que, naquele trabalho, parece ter provocado antagonismo entre ele (o potássio) e o magnésio. Neste ensaio, o teor de magnésio foi também um pouco menor, pelas razões já expostas no caso da casca.

Os dados do Quadro 10 mostram que não houve efeito do fósforo nos teores de óleo, nas sementes. Por outro lado, EL-HAMIDI, MOURSI \& AHMED (1968) não encontraram respostas à ação de nitrato de cálcio, no teor de óleo das sementes. Concluíram dizendo que os resultados por eles obtidos sugeriam que as características das sementes não são facilmente afetadas pelos fatores ambientais .

\section{CONCLUSÕES}

a) O fósforo incrementou significativamente a produção de frutos, em peso e número, por parcela, e o número de frutos, por cacho, e a produção de sementes, em gramas por cacho.

b) A ação do fósfòro foi maior no aumento do número de frutos e, dentro dos tipos de cachos, os primários foram os mais influenciados.

c) No peso de 100 sementes e no teor de óleo nas sementes, o efeito do fósforo não ficou bem caracterizado.

d) A adição de fósforo apresentou certa tendência em reduzir o teor de nitrogênio na casica, não afetou o seu próprio teor e os de potássio, cálcio e magnésio.

e) $\mathrm{Na}$ semente houve incremento do teor de fósforo com a aplicação deste elemento no solo.

\section{SLMMARY}

"EFFECTS OF RATES OF PHOSPHORUS IN CASTOR BEANS (RICINUS COMMUNIS, L.) cv. Campinas".

With the aim to verify as phosphorus can increase castor bean yield, an experiment was conducted, using the "Campinas" cultivar.

It was laid out during season of 1971-1972 and the experimental design was in randomized brockss, with five replications and six rates of phosphorus, $0-40-80-120-$ $160-200 \mathrm{~kg}$ of $\mathrm{P}_{2} \mathrm{O}_{5} / \mathrm{ha}$. 
According to the data, the following conclusions can be drawn.

There was an increase of the seed production of $320 \%$ when the data of the treatments with prosphorus were compared with that without phosphorus. This is due to the fact that phosphorus increased the number of fruits by raceme and by plot, the seed weight, and decreased the percentage of hulls in the fruits. Among the racemes, the first one gave better response to phosphorus.

Fertilizer phosphorus application increased the phosphorus content of the seed and showed a tendency to diminish the nitrogen content of the hulls.

The oil seed content was not affected by the phosphorus addition in soil.

\section{LITERATURA CITADA}

ANDREOLI, C. 1974. Efeitos de níveis de fósforo na produção da mamoneira (Ricimus communis L.) cultivada em um Latossol Roxo. Tese de graduação. Jaboticabal. 261.

BANZATTO, N.V. \& ROCHA, J.V.L. 1965. Florescimento e maturação dos cultivares de mamoneira "IAC-38" e "Campinas". Bragantia", 24 : XXIX-XXXII.

CONECCHIO FILHO, V.; ROCHA, J.L.V. \& FREIRE, E.S. 1963. Adubação da mamoneira. III. Experimento com doses crescentes de nitrogênio, fósforo e potássio. Pragantia, 22(2) : 765-775.

CATANI, R.A.; GALLO, J.R. \& GARGANTINI, H. 1965. Amostragem de solos, métodos de análise, interpretação e indicações gerais para fins de fertilidade. Inst. Agron. Campinas. Bolm n. ${ }^{0} 69$.

EL PARADI, T.A. 1969. Castor bean (Ricinus communis L.) Trop. Abstr., 24(9): $567-572$.

EL-HAMIDI, A.; MOURSI, M.A. \& AlIMED, S.S. 1968. Ef'fects of nitrogen and spacing on castor bean in sand soils in Egypt. Exp. Agric., 4:61-64.

ESPINDOLA, C.R.; TOSIN, W.A.C. \& PACCOLA, A.A. 1973. Levantamento pedológico da Fazenda Experimental de São Manuel. Anais do XIV Congr. Bras. Ciencia do Solo, 650-651, Sta. Maria. Rio Grande do Sul.

GLORIA, N.A. DA; CATANI, R.A. \& MATUO, T. 1965. O método de EDTA na determinação de cálcio e magnésio “trocável” do solo. Revta. agric., Piracicaba, 40 : $67-74$.

GURGEL, J.T.A. \& VALSECHI. O. 1952. Riqueza em óleo nas sementes, amêndoas e cascas das bagas de mamona. Anais Esc. sup. Agric. "Luiz de Queiroz", 9:271-284.

MALAVOLTA, E. 1965. Apuentes de classe n. ${ }^{\circ}$ 41. Fisiogênicas. Inst. Nac. Tecnológica Agropecuária. Buenos Aires.

MALAVOLTA, E. \& COURY, T. 1954. Apostila de práticas de Química Agrícola. Centro Acadêmico “Luiz de Queiroz”. Piracicaba.

NAKAGAWA, JULIO \& NEPTUNE, A.M.L. 1971. Marcha de absorção de nitrogsenio, fúsforo, potássio, cálcio e magnésio na cultura da mamoneira (Ricinus communis L.), cultivar 'Campinas'. Anais Fsc. sup. Agric. "Luiz de Queiroz", 28:323-3.37. 
NAKAGAWA. JÚLIO \& NETUNE, A.M.L. 1973. Absorção de nitrogênio, fósforo, potássio, cálcio e magnésio, pela cultura da mamoneira (Ricinus communs L.), cultivar 'IAC-38'. Revta. agric., 48(1) : 21-30.

NAKAGAWA, JÚlIO; NEPTUNE, A.M.L. \& JAHEN, A. 1974. Efeitos isolado e combinado de nitrogênio, fósforo e potássio em mamoneira (Ricinus communis L.), cultivares 'IAC-38' e 'Campinas'. Anais Esc. sup. Agric. "Luiz de ueiroz", 31:233-241 .

NAKAGAWA, JULIO; POLASTRE, R.; CANTARELLA, H. ; SARTORATO, A. \& JAEHN, A. 1975. Efeitos residuais de adubos fosfatados na mamoneira, 3.0 ano. Anais da V Jornada Científica da FCMBB, Botucatu, p. 32.

SOUZA, E.A.; FERREIRA, M.E.; BONO, G.M. \& BANZATTO, D.A. 1974. Efeitos da fertilização nitrogenada, fosfatada e potássica na prodıção da mamoneira (Ricimus communis L.). Científica, Jaboticabal, 2(2): 162-168. 
